\title{
OPEN SOURCE IMAGE-PROCESSING TOOLS FOR LOW-COST UAV-BASED LANDSLIDE INVESTIGATIONS
}

\author{
U. Niethammer ${ }^{\text {a, } *, \text { S. Rothmund }}{ }^{\text {a }}$, U. Schwaderer ${ }^{\text {a }}$, J. Zeman ${ }^{\text {a }}$, M. Joswig ${ }^{\text {a }}$ \\ ${ }^{\text {a }}$ Institute for Geophysics, University of Stuttgart - uwe.niethammer@geophys.uni-stuttgart.de
}

Commission I, WG I/V

KEY WORDS: UAVs, quad-rotor, landslide, photogrammetry

\begin{abstract}
:
In recent years, the application of unmanned aerial vehicles (UAVs) has become more common and the availability of lightweight digital cameras has enabled UAV-systems to represent affordable and practical remote sensing platforms, allowing flexible and highresolution remote sensing investigations. In the course of numerous UAV-based remote sensing campaigns significant numbers of airborne photographs of two different landslides have been acquired. These images were used for ortho-mosaic and digital terrain model (DTM) generation, thus allowing for high-resolution landslide monitoring. Several new open source image- and DTMprocessing tools are now providing a complete remote sensing working cycle with the use of no commercial hard- or software.
\end{abstract}

\section{INTRODUCTION}

Remote sensing has been an integral method of landslide investigations for many decades, with several different techniques being used (Mantovani et al., 1995). Traditional airborne- and satellite-based remote sensing techniques are suitable for landslide detection over areas of multiple square kilometres (Henry et al., 2002). However, data acquired with these methods is of neither sufficient resolution nor repeat rate to resolve the evolution of small landslide features, such as fissure structures or small displacements, which can provide significant information on landslide dynamics. Scientists are now beginning to turn to unpiloted aerial vehicles (UAVs) as a low-cost alternative for high-resolution data acquisition. In recent studies it has been shown that such low-cost approaches can be sufficient for reliable landslide analysis (Niethammer et al., 2011). Here, we investigate a low-cost UAV-system and an image processing chain based on open source tools for generating ortho-mosaics and digital terrain models (DTMs).

\subsection{Studied landslides}

Two landslides have been focused on for UAV-based landslide investigations. The Super-Sauze landslide (figure 1) is located on the north-facing slope of the Barcelonnette Basin (Southern French Alps). It extends over a horizontal distance of $850 \mathrm{~m}$ and occurs between an elevation of $2105 \mathrm{~m}$ at the crown and $1740 \mathrm{~m}$ at the toe with an average slope of $25^{\circ}$. Its total volume is estimated to be $750,000 \mathrm{~m}^{3}$. Sliding velocities range up to 0.4 $\mathrm{m}$ per day (Malet and Maquaire, 2003). The Heumoes landslide (figure 1) is located in the eastern Vorarlberg Alps, Austria, 10 $\mathrm{km}$ south-east of Dornbirn. It is approximately $2000 \mathrm{~m}$ in west to east direction and about $500 \mathrm{~m}$ at its widest extent in north to south direction. It occurs between an elevation of $940 \mathrm{~m}$ in the east and $1360 \mathrm{~m}$ in the west, slope angles of more than $60 \%$ can be observed as well as almost flat areas. Its total volume is estimated to be $9,400,000 \mathrm{~m}^{3}$ and average velocities amount to some cm per year (Lindenmaier et al., 2005).

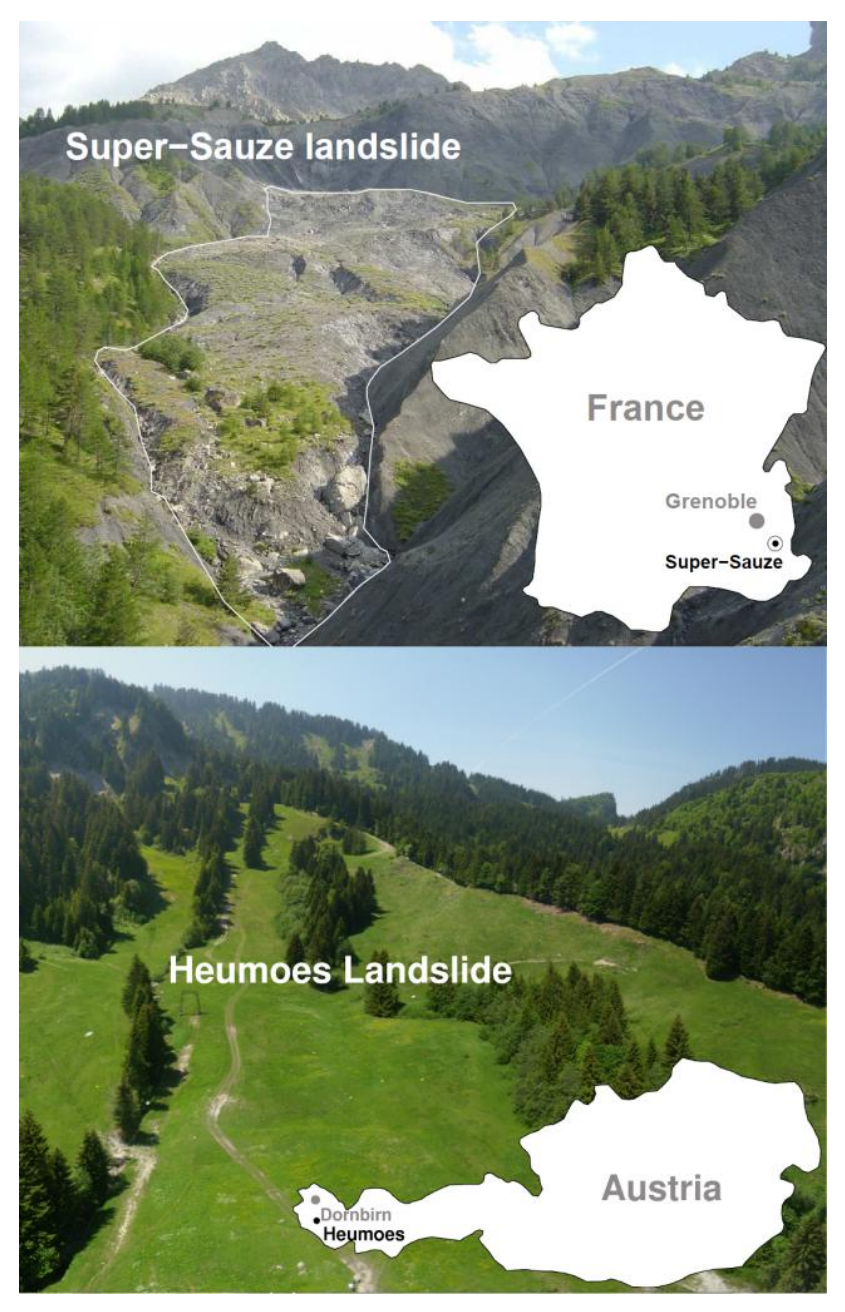

Figure 1. Top: view onto the Super-Sauze landslide, bottom: view onto the Heumoes landslide

\footnotetext{
* Corresponding author. This is useful to know for communication with the appropriate person in cases with more than one author.
} 


\section{IMAGE ACQUISITION}

\subsection{Quad-rotor UAV}

An open source quad-rotor UAV-system (Niethammer et al., 2009) was used for image acquisition (figure 2). The UAV was primarily controlled manually, since the use of autonomously controlled UAVs is tightly regulated by civil aviation and security authorities. However, manual flights require a good level of pilot skill and range restrictions are limiting the operational area to a few hundred meters.

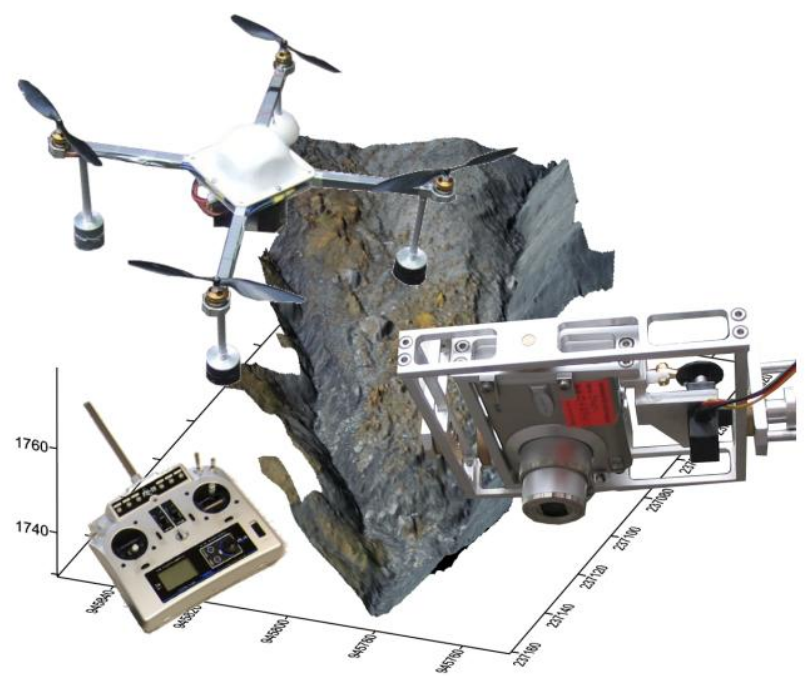

Figure 2. UAV-system for landslide investigations

\subsection{Flight planning}

Flight planning was carried out on site, where the area to be imaged was observed and suitable locations for take-off and landing could be identified. After launch, the quad-rotor was guided to the desired imaging flight altitude $\sim 200 \mathrm{~m}$ to provide a ground resolution of approximately $0.06 \mathrm{~m}$ per pixel. However, manual control of the UAV often leads to deviations in flight altitude and deviation of the image resolution has to be accepted. At the imaging altitude the UAV was hovered for about $30 \mathrm{~s}$ before vertical landing is initiated. After each flight, the area covered by the acquired photographs was verified on the camera directly.

\section{IMAGE PROCESSING}

UAV-based images often have to be rectified and merged to an ortho-mosaic for further analysis. In general, best results can be achieved by photogrammetric processing. In a first step a digital terrain model (DTM) is generated and images can then be projected onto the surface of the DTM. In a final step orthographic re-projection of the texture can then be applied (Wiesel, 1985). However, if no regular image-block alignment for photogrammetric computation can be managed (e.g. when using manual controlled UAVs), single image processing can be a promising approach to handle such kind of data.

\subsection{Single image rectification}

In a first step, optical distortion has to be corrected, for example by applying a third degree polynomial approach (Niethammer et al., 2009). An open source correction tool 'fulla' can also be found in the public domain (http://hugin.sf.net). In a second step each image is rectified using a non-parametric rectification approach (e.g. projective transformation, piecewise affine transformation, or polynomial transformation). Each rectification approach has to be selected in order to achieve the best result, which is dependent on the relief variation and the number of observed ground control targets (Niethammer et al., 2009). Nevertheless, in many cases the projective approach suggests to be an effective rectification method. Software tools for projective image rectification and geocoding are now available in the public domain (http://rectif.sf.net).

\subsection{Mosaic processing}

Rectified images can simply be merged to a large mosaic, but in most cases image borders remain visible (figure 3 ).

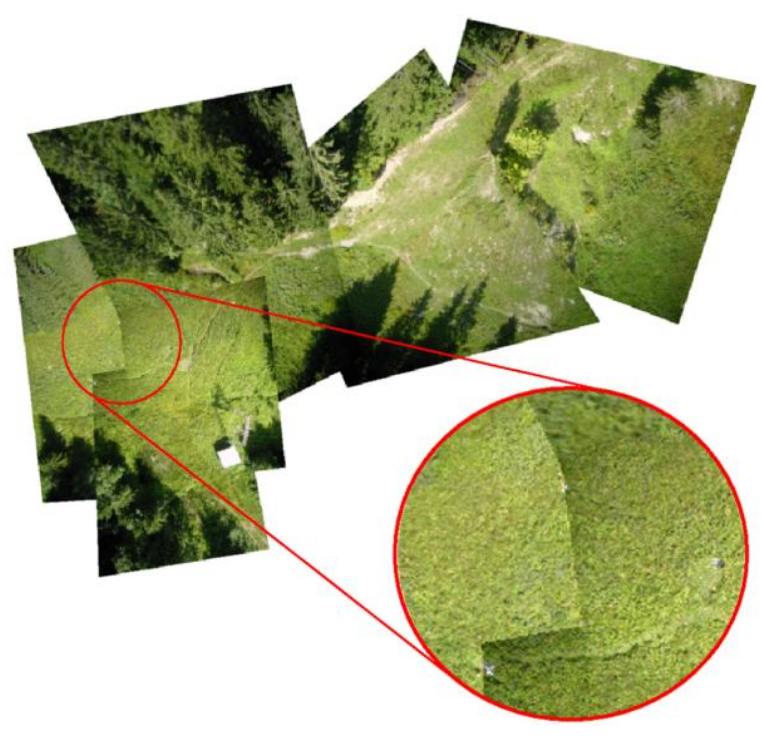

Figure 3. Mosaic of the Heumoes landslide with clearly visible image borders

However, this is not satisfying for further image analysis. Image blending can be a very effective method producing high quality mosaics, since radiometric variations of overlapping views often occur in UAV-acquired images.

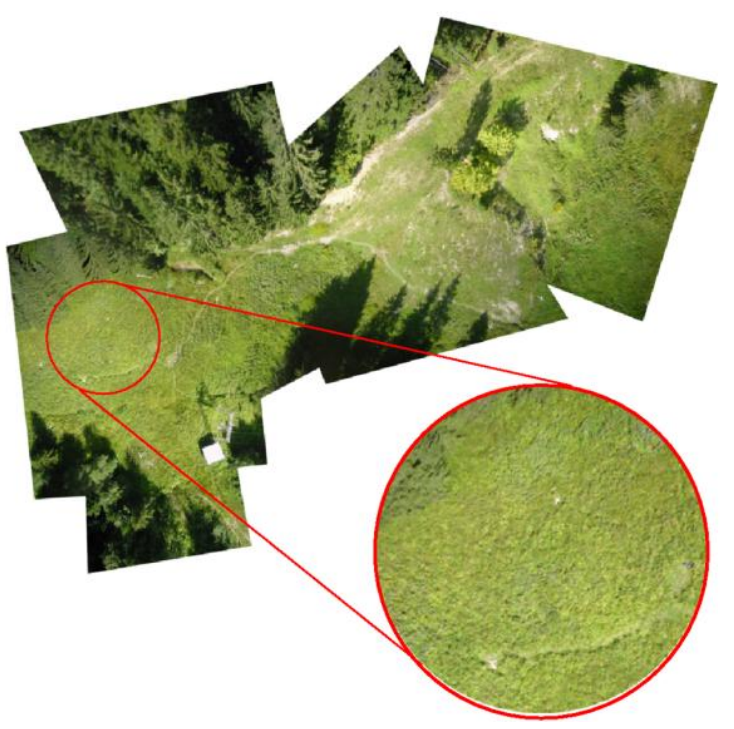

Figure 4. Seamless mosaic of the Heumoes landslide 
In recent studies novel approaches can be found for combining sets of registered images into a composite mosaic (Zomet et al., 2006; Pérez et al., 2003). Each image region keeps its own colour, brightness, and contrast and overlapping regions are blended with no seams (figure 4). An effective processing pipeline for geocoded ortho-mosaic blending is available in the public domain (http://build-mosaic.sf.net). This Linux bashscript is based on 'enblend', an open source tool available at http://enblend.sf.net.

\subsection{Photogrammetric processing}

Single image processing requires a significant amount of time and precision is limited when using plane rectified images for landslide analysis. Especially in irregular terrain approximate image transformation will not fully account for the effects of relief, and residual misalignments within the rectified image have to be accepted (Niethammer et al., 2011). However, misalignments can be avoided when using photogrammetry. Integrating DTM processing into the ortho-mosaic pipeline will significantly reduce errors in the final ortho-mosaic and additional three dimensional measurements can be made in a DTM. Currently, many commercial photogrammetry software packages are available, but most of them are expensive, yet not suitable for processing UAV-acquired photographs. In previous studies (Niethammer et al., 2011) photogrammetric processing of UAV-based images was made possible by using close-range VMS photogrammetry software (http://www.geomsoft.com) and 'GOTCHA' image matching from the University College London (Otto and Chau, 1989). Moreover, progress is also being made to streamline 3D-model processing (Niethammer et al., 2010) by using automated targetless structure-from-motion and multiview-stereo approaches to derive 3D models of the landslides topography (figure 5).

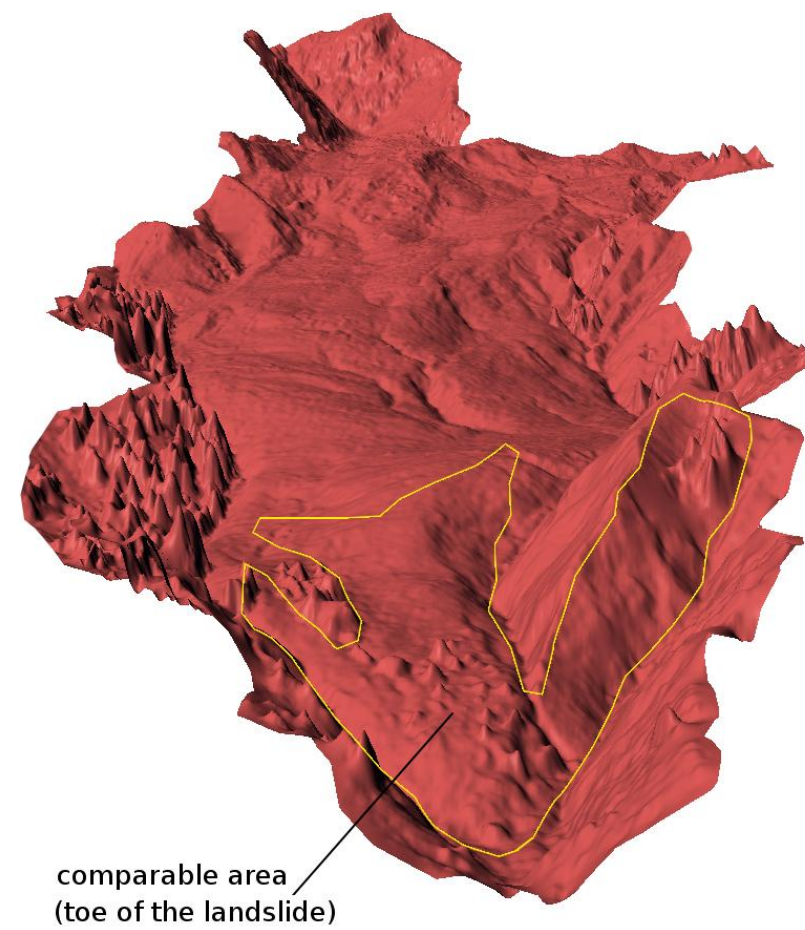

Figure 5. DTM of the entire Super-Sauze landslide ( $0.3 \mathrm{~m}$ grid $)$

These algorithms are also available in the public domain (Furukawa and Ponce, 2010; Snavely et al., 2008), providing an affordable basis for effective DTM processing, even if hundreds of images have to be processed. However, structure-from- motion approaches do not consider ground control point information and the coordinate system of the final 3D point cloud remains indeterminate. The point cloud's alignment can be adjusted by applying a spatial similarity transformation to all points of the indeterminate 3D model (Niethammer et al., 2010). Seven parameters are required for transformation, which can be calculated from a set of corresponding 3D point locations between the generated point cloud and measured ground control points. Currently, best alignment precisions are achieved by computing preliminary rectified orthophotos for point digitising in the indeterminate point cloud. Precisions of the digitized points are then supported by the texture information within the 3D model. In a final processing step the whole point cloud is then transformed into the destination coordinate system. Different approaches for transformation parameter computation are possible (Watson, 2006; Crosilla, 1999). A software tool based on the Procrustes analysis can also be found in the public domain (http://helmparms3d.sf.net).

\subsection{Photogrammetric precision analysis}

In previous studies (Niethammer et al., 2010 and 2011) closerange photogrammetry, MVS and terrestrial laser scanning (TLS) approaches have been compared and analysed at the toe of the Super-Sauze landslide. An analysis of the entire landslide could not be managed since no comparable data of the interesting time period has been available.

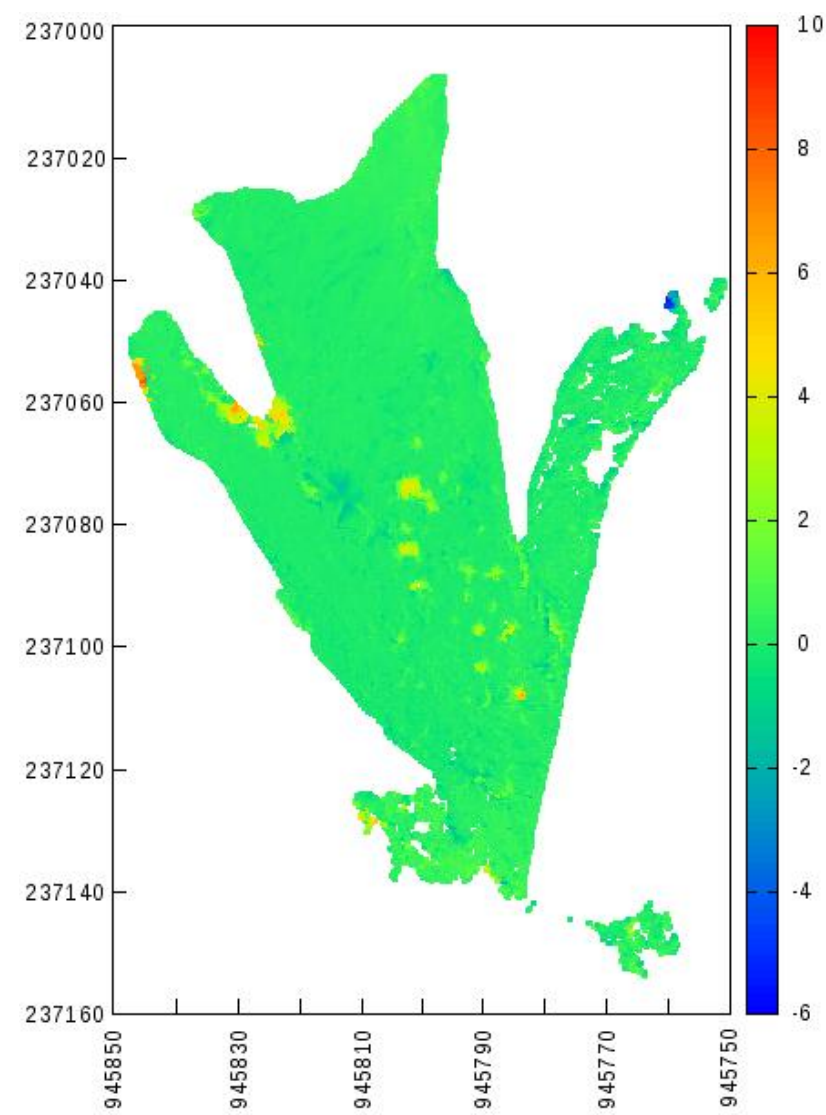

Figure 6. Altitude difference [m] at the toe (MVS -TLS)

A comparison of the DGPS-measured ground control points and a derived orthophoto from the entire MVS-based model showed a significant planar misfit over the $815 \mathrm{~m}$ DTM-length of $6 \mathrm{~m}$ in west to east direction. This misfit can be explained by justification errors of the 3D Helmert-transformation, as well as 
error propagation within the bundle-block processing of the very long and narrow model. Since the alignment of the entire landslide model could not be managed very precisely, an iterative closest point algorithm (Rusinkiewicz and Levoy, 2001) was applied. So the quality of the MVS-based model could easily be assessed by subtracting the elevations of two matched models. Here, a TLS of the toe of the Super-Sauze landslide (Travelletti et al., 2011) and the MVS-based point cloud of the toe of the landslide were compared. Both data sets were acquired at the same time period in order to avoid topographic changes of the landslide. In the vertical direction the RMS difference amounts $0.25 \mathrm{~m}$ with a standard deviation of $0.54 \mathrm{~m}$. Maximum deviations reach from -5.47 to $+8.55 \mathrm{~m}$ (figure 6). However, the most significant errors are induced by some small trees and bushes, the effects of which could not be reliably removed from the MVS-based point cloud.

The point density of the MVS-based digital surface model reaches up to 40 points per square meter and a separately processed model of the toe region with a point density of up to 70 points per square meter has been generated (Niethammer et al., 2010).

\section{LANDSLIDES ANALYSIS}

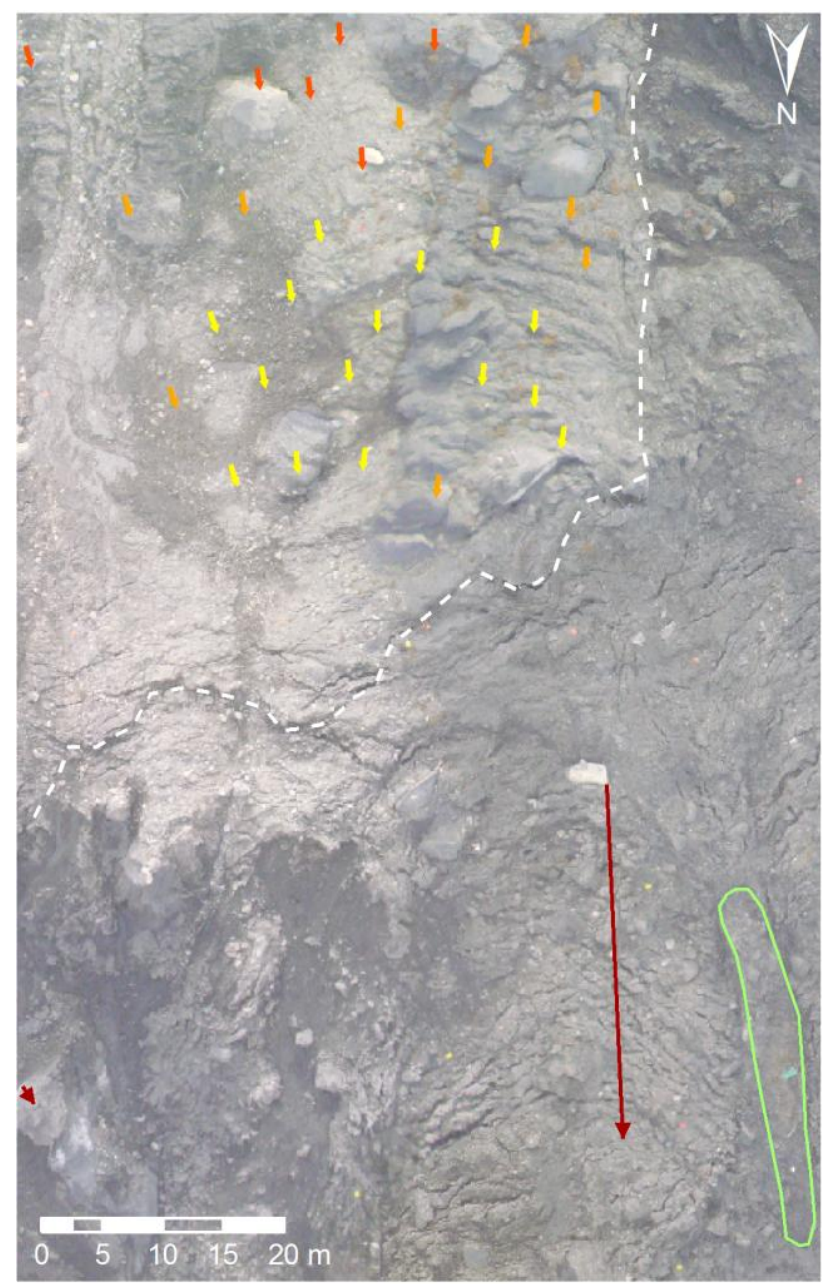

displacement vectors of the earthflow

$\downarrow 80,1-100,0 \mathrm{~cm}$

$\downarrow 60,1-80,0 \mathrm{~cm}$ $45,0-60,0 \mathrm{~cm}$

Figure 7. Horizontal displacements and scarp within the SuperSauze landslide in October 2008

\subsection{Orthophoto analysis}

Superficial displacements of landslides are of great interest and can be measured between orthophotos from different dates. Such measurements, for example, can be performed manually within a geographic information system (GIS) by identifying corresponding features and areas, such as rocks, stones and vegetation patches in different images (Niethammer et al., 2009) (figure 7, 8). Currently, many open source GIS software projects are available in the public domain. The most common projects are Qgis (http://www.qgis.org) and OpenJump (http://www.openjump.org) with a couple of software plugins which support many raster- and vector-based analysis- and processing tasks.

Displacement analysis can also be managed by applying automated image matching using correlation-based methods (Leprince et al., 2008) or by applying more sophisticated object- or feature-based matching techniques such as 'scaleinvariant feature transform' (SIFT) (Lowe, 2004). However, analysis of orthophotos is only providing horizontal information of landslide displacements.
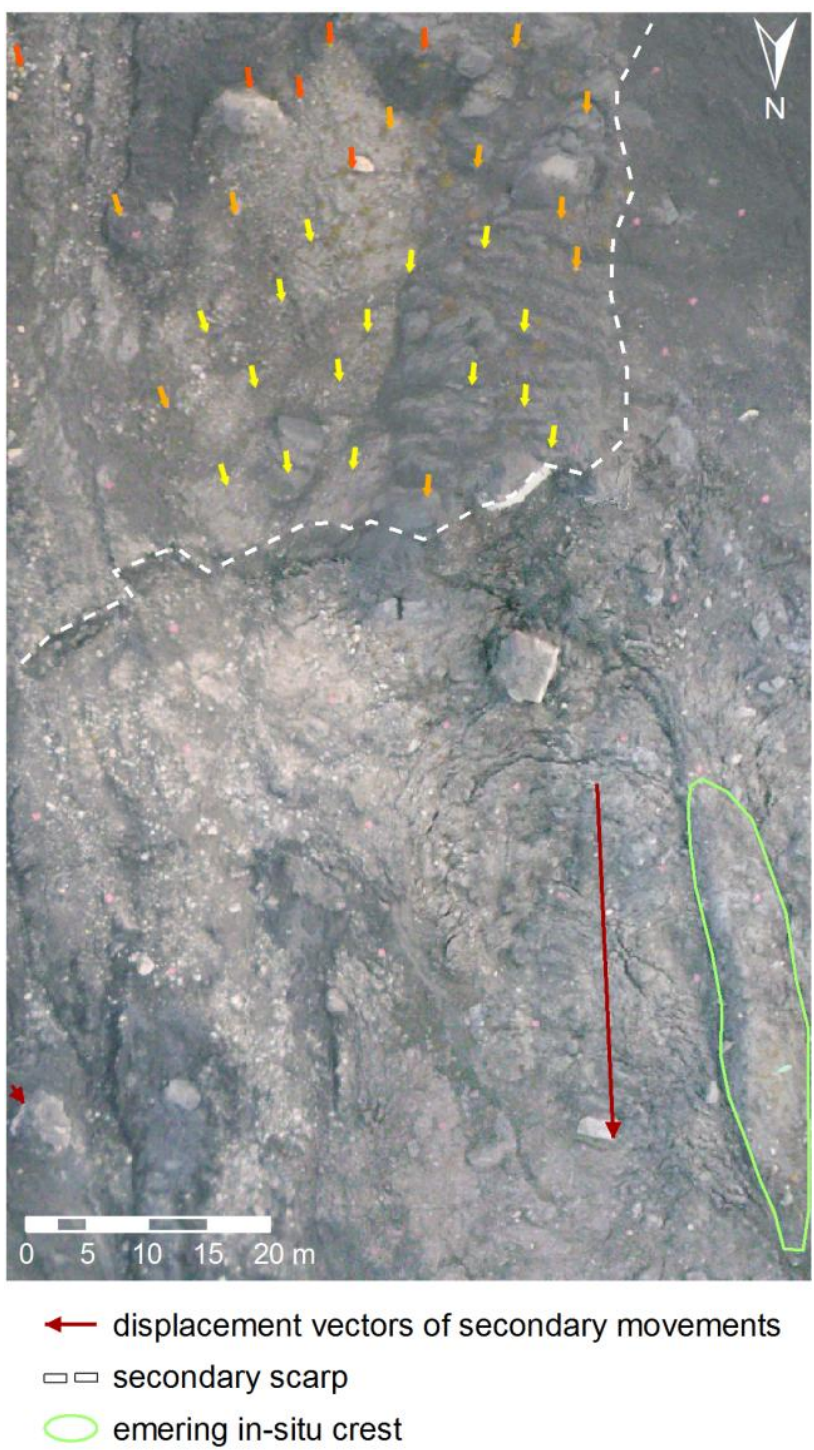

Figure 8. Horizontal displacements and scarp within the SuperSauze landslide in October 2009 


\subsection{DTM analysis}

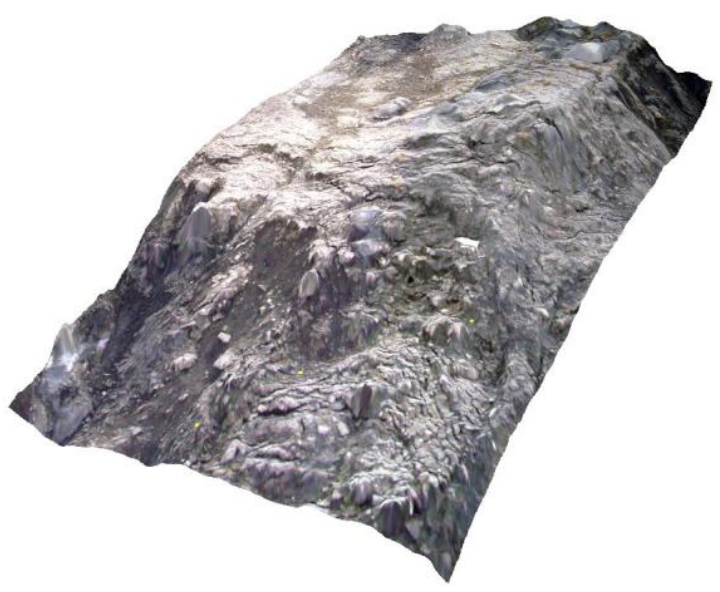

Figure 9. DTM of the upper part of the Super-Sauze landslide in October 2008

Digital terrain models are often used for mass-balancing in landslides research. This is commonly managed by computing the altitude difference between two different DTMs (figures 9, $10,11)$. This technique only provides vertical information of the landslide, and it has to be emphasized that both horizontal and vertical surface information are not sufficient for representative mass-balancing of landslides, since additional subsurface displacements also have to be regarded. Currently such information cannot be acquired by remote sensing techniques and direct subsurface measurements have to be applied.

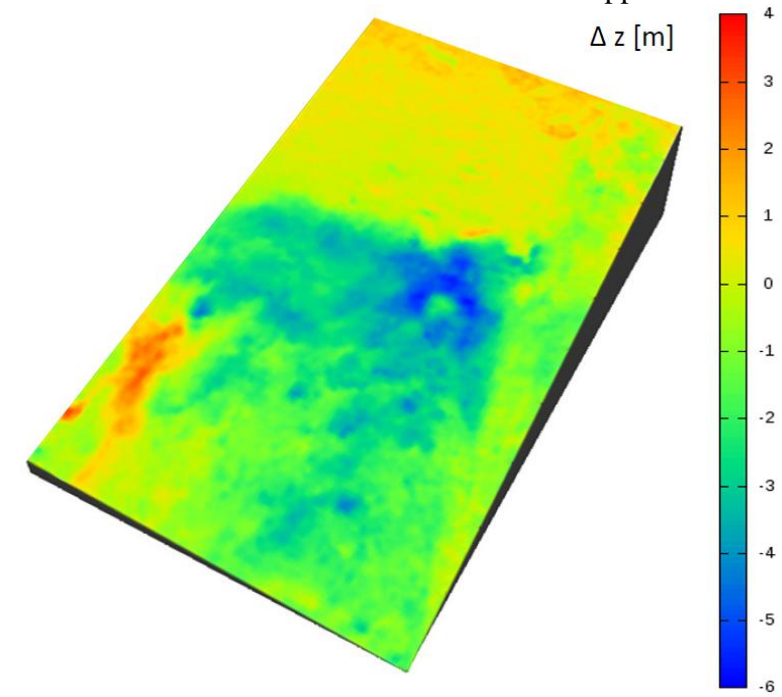

Figure 10. Altitude difference map between Oct. 2008 and Oct. 2009, upper part of the Super-Sauze landslide

Geotechnical, geological and hydrological soil parameters may provide enough information for the modelling of the subsurface displacements. In recent studies it is pointed out that some of the subsurface data (e.g. soil moisture (Niethammer et al., 2009) and medial soil grain size) may be gained from UAV-based high-resolution remote sensing data. UAV-based measurements of changes of landslide extension and topography may also provide interesting boundary conditions for modellers. These data can be used to verify the transferability of models into the real world with more realistic parameters than laboratory-based landslide experiments (Germer and Braun, 2011).

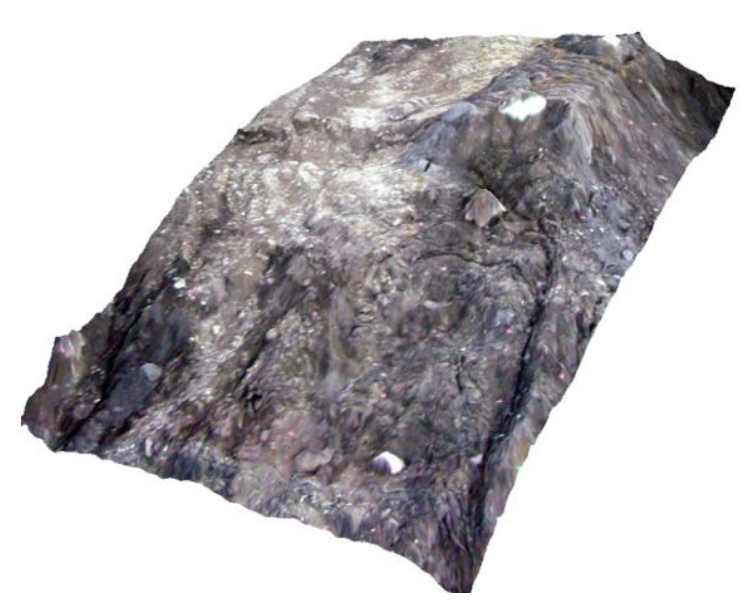

Figure 11. DTM of the upper part of the Super-Sauze landslide in October 2009

\subsection{Geomatics in landslides research}

Within the last decade a growing research interest for geomatics, a new discipline for many purposes of geographic knowledge discovery can be noticed (Gallerini et al., 2010).

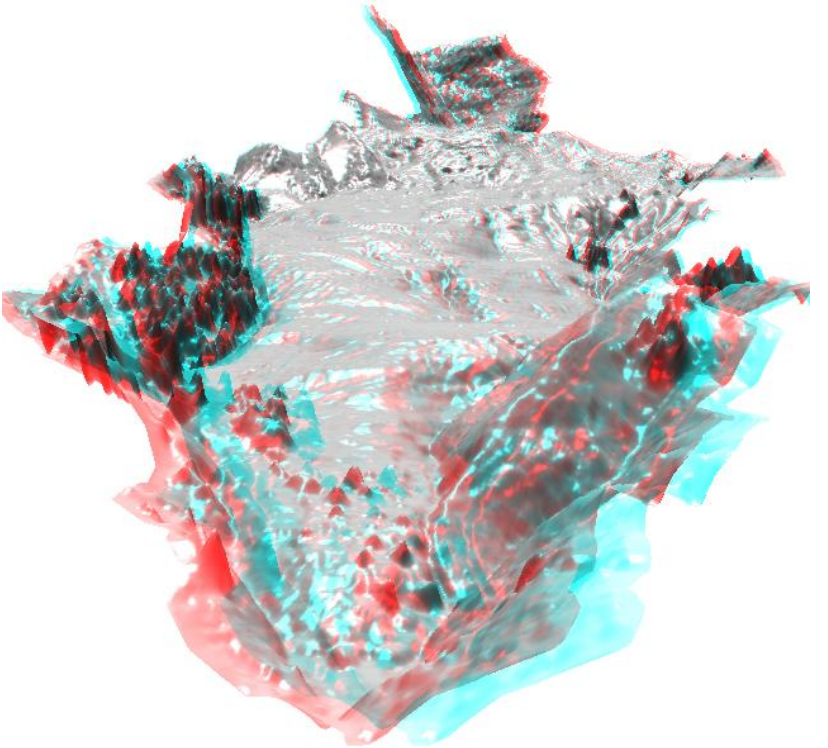

Figure 12. Virtual 3D anaglyph of the Super-Sauze landslide (red/cyan glasses are required for full 3D impression)

Geomatics has been defined as "the science of acquisition, management, modelling, analysis and representation of spatial data and processing with specific consideration of problems related to spatial planning, land use, land development and environmental issues" (Grun, 1998). Just in the field of landslides research many different spatial data sets have to be analysed from a global point of view. For example virtual UAVbased 3D models (figure 12), seismic 3D subsurface profiles, as well as different hydrological and morphological 3D variations may be visualized and analysed together in virtual space. In the future such new opportunities may lead to a better understanding of the interactions between many different landslide parameters that are supposed to be the main trigger mechanisms of landslide hazards. Landslide models may also be visualized and discussed, and consequences of different landslide event forecasts may be presented to the local 
inhabitants in order to promote sensitivity against dangerous developments, such as deforestation, road works, or mining.

\section{CONCLUSIONS}

Within this study, a couple of public domain image processing tools for low-cost ortho-rectification and mosaic blending were used. Different open source GIS projects have also been made available, thus enabling analysis of the planar remote sensing data. Even photogrammetric processing of hundreds of UAVbased images acquired with uncalibrated cameras was managed by applying open source software tools. The used algorithms can easily handle unordered image collections and have provided digital surface models of landslides without any ground control point information. The density and accuracy of MVS-based models is comparable to common photogrammetric methods, but it has to be ensured that long and narrow models will not be twisted by error propagation within the bundle-block processing. Overall, it can be concluded that a complete remote sensing working cycle with no commercial hardware or software is now possible. However, many of these softwaretools are only supplied in a very sparse command-line beta version. The user also has to prepare and convert input data between many different data formats. Especially some photogrammetric tools for registration and orthophoto processing are currently missing. Consequently, the development of such software-tools is advised in further studies.

\section{REFERENCES}

Crosilla, F., 1999. Procrustes analysis and geodetic sciences. In: Krumm, F., Schwarze, V.S. (Eds.), Technical Reports. Department of Geodesy and GeoInformatics, University of Stuttgart, Part I, pp. 69-78.

Furukawa, Y. and Ponce, J., 2010. Accurate, dense, and robust multi-view stereopsis. In: IEEE transactions on pattern analysis and machine intelligence, 32(8), pp. 1362-1376.

Gallerini, G., Susini, S., Bruciatelli, L., De Donatis, M., 2010, Geomatics and geo-tourism: San Bartolo Natural Park case study (Pesaro, Italy). Geology of the Adriatic area, Special Publication, 3, pp. 167-178.

Germer, K. and Braun, J., 2011. Effects of Saturation on Slope Stability: Laboratory Experiments Utilizing External Load. Vadose Zone Journal, 10(2), pp. 477-486.

Grun, A., 1998. Geomatic Engineering and Environmental Engineering. Geomatics Information Magazine, 12, pp. 30-33.

Henry, J.-B., Malet, J.-P., Maquaire, O., Grussenmeyer, P., 2002. The use of small-format and low-altitude aerial photos for the realization of high-resolution DEMs in mountainous areas: application to the Super-Sauze earth-flow (Alpes-de-HauteProvence, France). In: Earth Surf. Process. Landforms, 27(12), pp. 1339-1350.

Leprince, S., Berthier, E., Ayoub, F., Delacourt, C., Avouac, J.P., 2008. Monitoring earth surface dynamics with optical imagery. EOS Transactions, American Geophysical Union, 89(1), pp. 1-2.

Lindenmaier, F., Zehe, E., Dittfurth, A., Ihringer, J., 2005. Process identification at a slow-moving landslide in the Vorarlberg Alps. Hydrological Processes, 19, pp. 1635-1651.
Lowe, D., 2004. Distinctive image features from scale-invariant keypoints. International Journal of Computer Vision, 60(2), pp. 91-110.

Mantovani, F., Soeters, R., Van Westen, C.J., 1996. Remote sensing techniques for landslide studies and hazard zonation in Europe. Geomorphology, 15(3-4), pp. 213-225.

Malet, J.P. and Maquaire, O., 2003. Black marl earthflows mobility and long-term seasonal dynamic in southeastern France. In: Picarelli, L. (ed.), Proceedings of the International Conference on Fast Slope Movements: Prediction and Prevention for Risk Mitigation, Bologna, Patron Editore, pp. 333-340.

Niethammer, U., Rothmund, S., Joswig, M., 2009. UAV-based remote sensing of the slowmoving landslide Super-Sauze. In: Malet, J.-P., Remaître, A., Boogard, T. (Eds.), Proceedings of the International Conference on Landslide Processes: From Geomorphologic Mapping to Dynamic Modelling, CERG Editions, Strasbourg, pp. 69-74.

Niethammer, U., Rothmund, S., James, M.R., Travelletti, J., Joswig, M., 2010. UAV-based remote sensing of landslides. In: Int. Arch. Photogram. Rem. Sens. Spatial Inf. Sciences, Vol. XXXVIII. ISPRS Comm. V., Newcastle-upon-Tyne, U.K, pp. 496-501.

Niethammer, U., James, M.-R., Rothmund, S., Travelletti, J., Joswig, M., 2011. UAV-based remote sensing of the SuperSauze landslide: Evaluation and results. Eng. Geol., doi:10.1016/j.enggeo.2011.03.012.

Otto, G.P., and Chau, T.K.W., 1989. Region-growing algorithm for matching of terrain images. Image Vision Comp., 7, pp. 8394.

Pérez, P., Gangnet, M., Blake, A., 2003. Poisson image editing. In: Proc. SIGGRAPH, Jul. 2003, pp. 313-318.

Rusinkiewicz, S. and Levoy, M., 2001. Efficient variants of the ICP algorithm. In: Proc. of the third international conference on 3-D digital imaging and modelling, doi: 10.1109 / IM.2001.924423, pp.145-152.

Snavely, N., Seitz, S.M., Szeliski, R., 2008. Modeling the World from Internet Photo Collections. International Journal of Computer Vision, 80(2), pp. 189-210.

Travelletti, J., Malet, J.P., Delacourt, C., 2011. Multi-dates correlation of Terrestrial Laser Scanning data for the characterization of landslide kinematics. Geophysical research abstracts, vol. 13, Vienna.

Watson, G.A., 2006. Computing Helmert transformations. Journal of Computational and Applied Mathematics, 197(2), pp. 387-394.

Wiesel, J., 1985. Digital image processing for orthophoto generation. Photogrammetria, 40(2), pp. 69-76.

Zomet, A., Levin, A., Peleg, S., Weiss, Y., 2006. Seamless Image Stitching by Minimizing False Edges. IEEE image processing, 15(4), pp. 969-977. 